EGU2020-4106

https://doi.org/10.5194/egusphere-egu2020-4106

EGU General Assembly 2020

(c) Author(s) 2020. This work is distributed under

the Creative Commons Attribution 4.0 License.

\title{
Downscaling flows in the water-food-energy Nexus
}

\author{
Stefan C. Dekker', Maria J. Santos ${ }^{2}$, Hanneke Van 'tVeen², and Detlef P. van Vuuren ${ }^{1,3}$ \\ ${ }^{1}$ Utrecht University, Environmental Sciences, Copernicus Institute of Sustainable Development, Utrecht, The Netherlands \\ ${ }^{2}$ University Research Priority Program in Global Change and Biodiversity and Department of Geography, University of \\ Zurich, Zurich, Switzerland \\ ${ }^{3}$ PBL Netherlands Environmental Assessment Agency, The Hague, the Netherlands
}

The variabilities in both time and space of the flows between the components of the water-foodenergy are dependent on many driving factors. In this study we use global scenarios from the Integrated Assessment Model IMAGE to analyse future changes in flows in the water, food and energy nexus. With Sankey diagrams we show how flows between energy and food production will likely increase by $60 \%$ and water consumption by $20 \%$ in 2050 by using a reference scenario. The inclusion of climate action policies, combined with dietary changes, increased yield efficiency and food waste reduction leads to similar resources uses of water and land, and much lower greenhouse gas emissions compared to 2010.

We found that based on data, spatial scales are an important but complicating factor in nexus analysis. This is because different resources have their own physical and spatial scale characteristics within the nexus. To examine the effect of scaling on future nexus development, we analyse how local decisions and local resource availability of the use of biomass as energy source impacts other resources. Biomass use potentially impacts forest systems and might compete with land for food and water resources within the nexus. The use of biomass and more specifically charcoal will likely further increase mainly due to urbanization in developing countries. We have examined how different shared socio economic pathway (SSP) scenarios result in (i) future demand for biomass for energy and compare those to measured (with remote sensing) and modelled net primary productivity values of forested systems, (ii) estimate the amount of land needed for biomass production that might compete with food production, and (iii) estimate the water amount needed to produce biomass to meet the different biomass demands. We found that current productivity of non-protected forests is globally higher than the demand, but regionally it closely meets the demand for tropical areas in Central America and Africa. This while tropical areas in South America and Indonesia show decreasing biomass demands for energy for the SSP1-SSP3 scenarios. From this analysis we clearly see differences at regional scales in the competition between the resources land and water are found.

We conclude that a nexus framework analysis which estimates flows between the different components across scales is fundamental to understand system sustainability. Such approach benefits from combining global scenarios of Integrated Assessment models with local conditions to understand the sustainability in the nexus in time and space. 
